\title{
Prevalence and clinical significance of acquired left coronary artery fistulas after surgical myectomy in patients with hypertrophic cardiomyopathy
}

\author{
Aurelio Sgalambro, MD, ${ }^{\mathrm{a}}$ Iacopo Olivotto, MD, ${ }^{\mathrm{a}}$ Alessandra Rossi, MD, ${ }_{\mathrm{b}}$ Stefano Nistri, MD, ${ }^{\mathrm{a}}$ \\ Katia Baldini, MD, ${ }^{\mathrm{a}}$ Massimo Baldi, MD, ${ }^{\mathrm{a}}$ Pierluigi Stefano, MD, ${ }^{\mathrm{b}}$ David Antoniucci, MD, ${ }^{\mathrm{c}}$ \\ Francesca Garbini, MD, ${ }^{\mathrm{d}}$ Franco Cecchi, MD, ${ }^{\mathrm{a}}$ and Magdi H. Yacoub, MD, FRS ${ }^{\mathrm{e}}$
}

\begin{abstract}
Objectives: The relevance of iatrogenic left coronary artery fistulas complicating surgical myectomy in patients with hypertrophic cardiomyopathy is not known. We prospectively defined the echocardiographic features, prevalence, and clinical significance of left coronary artery fistulas in 40 consecutive patients with hypertrophic cardiomyopathy undergoing extended septal myectomy.
\end{abstract}

\begin{abstract}
Methods: Echocardiographic analysis was performed preoperatively and 1 and 6 months after surgical intervention. Diagnosis of left coronary artery fistulas required evidence of diastolic flow draining from the left ventricular wall into the left ventricular cavity according to prespecified criteria.

Results: Left coronary artery fistulas were detected in $9(23 \%)$ of the 40 study patients as a single occurrence in all except 1 patient, who had multiple fistulas. At 6 months, left coronary artery fistulas could still be detected in only 2 of the 9 patients. Of these, 1 patient remained asymptomatic but continued to show left coronary artery fistula persistence at 37 months postoperatively. The other, a woman with prior alcohol septal ablation, had progressive severe symptoms that required percutaneous closure of the fistula with a covered stent after angiographic identification of a large first septal branch fistula associated with distal left anterior descending coronary artery steal.
\end{abstract}

Conclusions: In patients with hypertrophic cardiomyopathy, left coronary artery fistulas are common in the early period after surgical myectomy, although their echocardiographic prevalence is dependent on operator awareness. Most left coronary artery fistulas heal spontaneously. Occasionally, however, fistulas can persist and cause symptoms requiring therapeutic intervention. (J Thorac Cardiovasc Surg 2010;140:1046-52)

Coronary artery fistulas are usually congenital in origin, with an estimated prevalence between $0.002 \%$ and $0.2 \%$ in coronary angiographic studies. ${ }^{1}$ In patients with hypertrophic cardiomyopathy (HCM), spontaneously occurring left coronary artery fistulas (LCAFs) have been described anecdotally and might represent a cause of angina because of the coronary steal phenomenon. ${ }^{2-4}$

Acquired LCAFs caused by a variety of conditions, ${ }^{5-10}$ including trauma, ${ }^{5}$ myocardial infarction, ${ }^{6}$ endomyocardial biopsy, or percutaneous transluminal coronary angioplasty, ${ }^{7}$ have been reported. In patients with HCM, Buchwald and colleagues ${ }^{11}$ first described the occurrence of LCAFs as a complication of septal myectomy, followed by a small number of isolated case reports ${ }^{11-18}$ and a single retrospective series. ${ }^{19}$

From the Referral Center for Myocardial Diseases, ${ }^{a}$ the Cardiac Surgery Unit, ${ }^{\mathrm{b}}$ Invasive Cardiology, ${ }^{c}$ and the Department of Pathology, ${ }^{d}$ Careggi University Hospital, Florence, Italy; and Imperial College, ${ }^{\mathrm{e}}$ London, United Kingdom, and the University of Florence, Florence, Italy.

Disclosures: None.

Received for publication June 5, 2009; revisions received Jan 14, 2010; accepted for publication Feb 8, 2010; available ahead of print May 17, 2010.

Address for reprints: Magdi H. Yacoub, MD, FRS, Imperial College London, Heart Science Centre, Harefield, Middlesex, UB9 6JH, United Kingdom (E-mail: m.yacoub@imperial.ac.uk).

0022-5223/\$36.00

Copyright (c) 2010 by The American Association for Thoracic Surgery doi:10.1016/j.jtcvs.2010.02.020
The exact incidence and clinical relevance of surgical LCAFs in patients with HCM remain poorly defined. We here present the first prospective assessment of the prevalence, echocardiographic features, and natural history of LCAFs complicating surgical myectomy in a consecutive series of patients with HCM.

\section{MATERIALS AND METHODS Patients}

From November 2005 to November 2008, 40 consecutive patients (26 male patients; age, $45 \pm 13$ years; age range, 19-72 years) underwent extended septal myectomy with left ventricular (LV) outflow tract remodeling $^{20,21}$ performed by the same operator (MHY) for relief of symptomatic outflow tract, midventricular obstruction, or both. Clinical diagnosis of HCM was based on the demonstration by means of 2-dimensional echocardiographic analysis of a hypertrophied and nondilated left ventricle (wall thickness of $\geq 15 \mathrm{~mm}$ in adults) in the absence of another cardiac or systemic disease capable of producing a similar degree of hypertrophy. ${ }^{22}$

\footnotetext{
Study Protocol

Preoperatively, all patients underwent clinical assessment, detailed transthoracic echocardiographic analysis, and coronary angiographic analysis. After surgical intervention, first clinical and echocardiographic assessments were performed at 1 and 6 months. Adjunctive echocardiographic controls were repeated, as required, during follow-up. The mean follow-up duration was $13 \pm 10$ months. Postoperatively, all patients received maintenance treatment with $\beta$-blockers; either nadolol (40-80 mg) or bisoprolol (5-10 $\mathrm{mg}$ ) was used. During the study period, anticoagulation with warfarin (substituted with full-dose low-molecular-weight heparin in the
} 

Abbreviations and Acronyms
$\mathrm{HCM}=$ hypertrophic cardiomyopathy
LCAM = left coronary artery fistula
$\mathrm{LV}=$ left ventricular
NYHA $=$ New York Heart Association
$\mathrm{SAM}=$ systolic anterior movement of the mitral leaflets

perioperative period) was instituted in patients with a history or in-hospital documentation of paroxysmal or chronic atrial fibrillation $(n=6)$. Lowdose aspirin was prescribed to 3 additional patients without atrial fibrillation because of multiple coexistent cardiovascular risk factors.

\section{Echocardiographic Analysis}

Echocardiographic evaluations were performed with a commercially available machine (Esaote MyLab 30 or Esaote CV 50). LV outflow tract gradients were measured in the left lateral decubitus position with continuous-wave Doppler interrogation in the apical 5-chamber view, taking care to avoid confusion or distraction of the waveform by the mitral regurgitation jet. ${ }^{22}$ The diagnosis of an LCAF according to established criteria $^{9,12-19}$ required the demonstration by means of color flow mapping, pulsed-wave, and continuous-wave Doppler ultrasonographic analysis of a diastolic flow originating from 1 or more LV walls (usually the septum) and draining into the ventricular cavity that was clearly distinguished from septal perforation or from an aortic regurgitation jet (Figure 1).

\section{Surgical Technique}

After cardiopulmonary bypass was established, cold antegrade crystalloid or blood cardioplegia was used for myocardial protection. The aortic valve was then exposed through a long hockey-stick incision that extended into the base of the noncoronary sinus of Valsalva. The subvalvular region was exposed by retracting the aortic leaflets. A vertical incision was performed in the interventricular septum, starting just below the right and middle thirds of the base of the right coronary cusp and extending deep into the ventricle to a level just below the tip of the anterior papillary muscle. A wedge of fibromuscular tissue was excised starting from the vertical incision and extending toward the left fibrous trigone. The latter was carefully mobilized by extending the incision laterally into the fibrous trigone, thus opening the hinge mechanism between the muscular ventricular septum and the subaortic curtain. ${ }^{20}$ The incision was gradually and slowly deepened until the free lateral border of the anterior leaflet of the mitral valve could be clearly seen. Any bridging tissue between the mitral leaflet and muscular ventricular septum was excised. ${ }^{20}$ The right fibrous trigone was mobilized by means of excision of the wedge of abnormal tissue in the angle between the membranous septum and subaortic curtain. Minimal extension of the incision laterally into the fibrous trigone was then made, avoiding injury to the bundle of His. ${ }^{20}$ In selected patients with midventricular obstruction, the intervention was completed through an apical approach. A fish-mouth incision was performed, followed by excision of myocardium and dissection of the papillary muscles.

\section{RESULTS}

\section{Preoperative Features}

The mean age of the 40 study patients was $45 \pm 13$ years, and 26 were male. Maximum septal thickness was $27 \pm 5 \mathrm{~mm}$

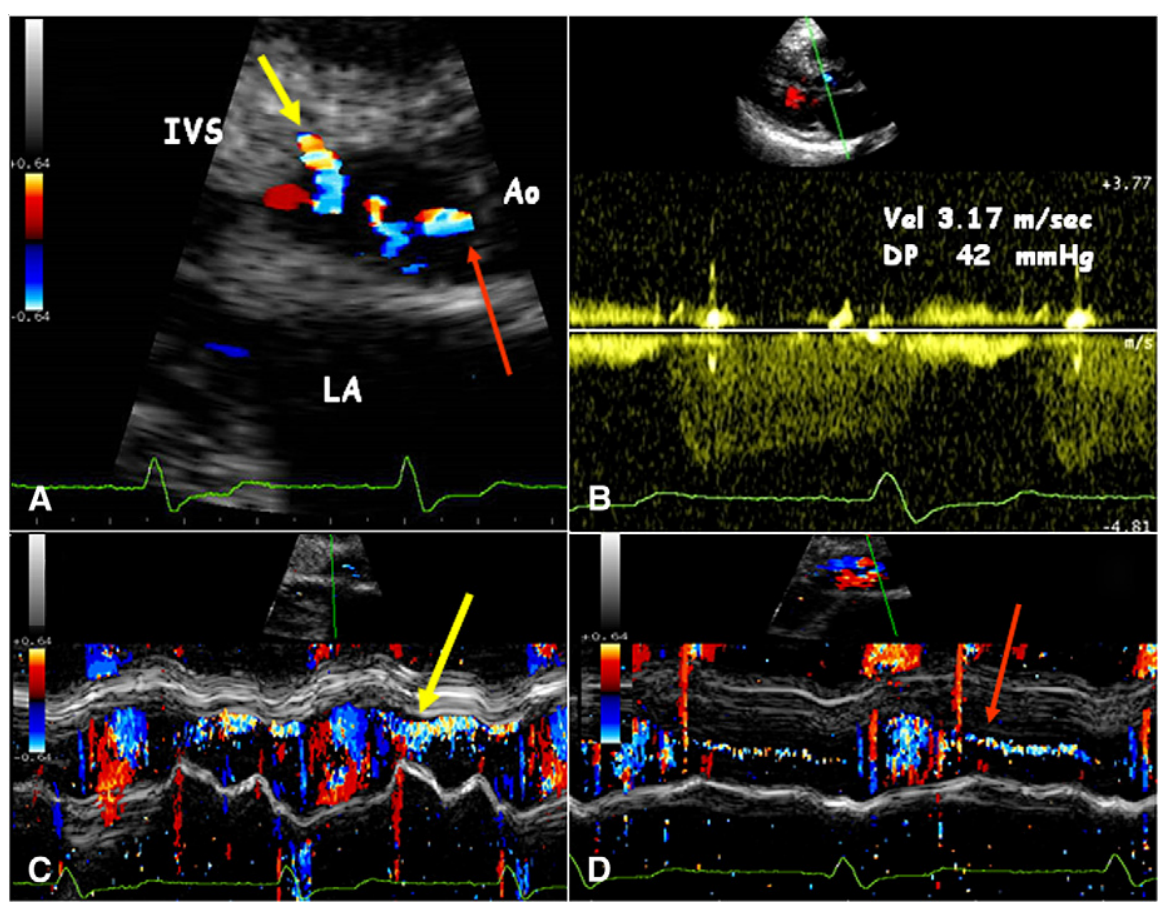

FIGURE 1. Echocardiographic diagnosis of acquired septal left coronary artery fistulas (LCAFs) after surgical myectomy. The required criteria for LCAF diagnosis used in the present study are shown. A, In the magnified left parasternal long-axis view, an LCAF, originating from the ventricular septum (IVS) and draining in the outflow tract (yellow arrow), is evident and easily differentiated from a mild aortic regurgitation jet (red arrow). Ao, Aorta; LA, left atrium. B, Continuous-wave Doppler scanning recorded a holodiastolic flow, with a maximal velocity of $3.17 \mathrm{~m} / \mathrm{s}$ (peak gradient, $42 \mathrm{~mm} \mathrm{Hg}$ ). C and D, Color M-mode scanning: LCAF flow bordered the left septal endocardial surface (C, yellow arrow), whereas the aortic regurgitation was situated in the center of the outflow tract (D, red arrow). 


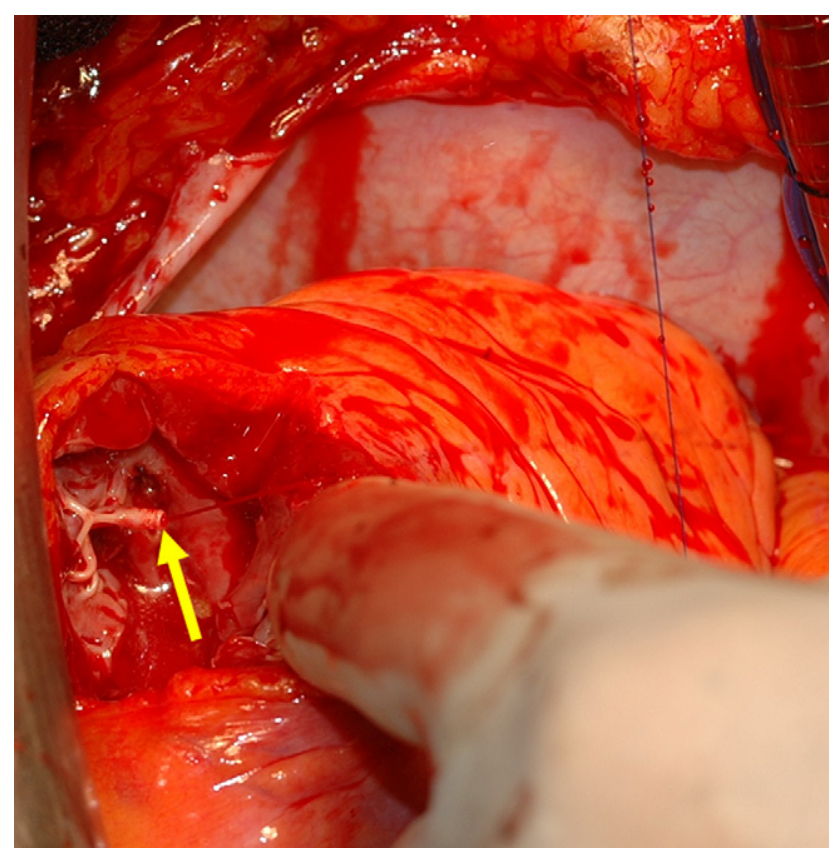

FIGURE 2. Intraoperative aspect of a large left coronary artery fistula generated during surgical myectomy conducted through the transaortic and transapical approaches for severe midventricular obstruction. Intraoperative selective intracoronary injection showed abundant flow originating from a large perforator branch (arrow). This fistula was surgically closed, and no shunt resulted at postoperative echocardiographic analysis.

on average; the median value was $25 \mathrm{~mm}$. All patients had severe intracavitary LV obstruction associated with class III symptoms. The obstruction was subaortic and related to systolic anterior movement of the mitral leaflets (SAM) in $34 \mathrm{pa}-$ tients (peak gradient in basal conditions, $70 \pm 32 \mathrm{~mm} \mathrm{Hg}$ ) and midventricular in 5 patients (peak gradient, $37 \pm 24$ $\mathrm{mm} \mathrm{Hg}$ ). Mitral regurgitation was present in resting conditions in $37(92 \%)$ patients and graded as mild in 21 , moderate in 12 , and severe in 4 . Three patients had previously undergone percutaneous alcohol septal ablation, with no $(\mathrm{n}=1)$ or only temporary $(n=2)$ relief of symptoms related to outflow obstruction.

\section{Operative Results}

Thirty-three patients underwent operations exclusively through the transaortic approach $(83 \%)$. In $7(17 \%)$ patients both transaortic and apical approaches were required because of severe midventricular obstruction. In 1 patient a large LCAF was detected intraoperatively after septal resection and was surgically closed (Figure 2). There were no perioperative deaths, and no major complications occurred during or after surgical intervention; in 1 patient accidental septal perforation occurred, resulting in mild left-to-right ventricular shunt, which healed spontaneously. One $(3 \%)$ patient with prior alcohol septal ablation had atrioventricular block requiring pacemaker implantation.

The average postoperative peak gradient at 1 month was $11 \pm 15 \mathrm{~mm} \mathrm{Hg}$; at this time, 2 patients had small residual gradients (31 and $38 \mathrm{~mm} \mathrm{Hg}$, respectively) because of mild persistent SAM. No significant change was observed at 6 months. Moreover, 3 of the 40 study patients showed moderate mitral regurgitation 1 month after surgical intervention. In 2 of these 3 patients, in whom the incompetence was related to SAM, the degree of mitral regurgitation had decreased to mild at 6 months after appropriate titration of $\beta$-blocker therapy. In the third patient mitral regurgitation remained moderate at 6 months; this was likely due to a primary valve defect because it was centrally directed and occurred in the absence of significant SAM or outflow gradient. All patients derived marked symptomatic improvement, with $28(70 \%)$ patients in New York Heart Association (NYHA) class I and $12(30 \%)$ in NYHA class II at final evaluation.

\section{Prevalence of LCAFs}

Preoperatively, none of the patient had evidence of LCAFs into the LV cavity. In 1 patient a small, spontaneously occurring LCAF was seen in the right ventricular cavity, originating from the apical wall. After surgical intervention, the diagnosis of LCAF was made in 9 of 40 patients, a $23 \%$ prevalence (Table 1). In 8 of the 9 patients, a single anomalous communication was found, originating from the

TABLE 1. Individual features of patients with acquired LCAFs

\begin{tabular}{cclcc}
\hline Patient no. & Age $(\mathbf{y}) / \mathbf{s e x}$ & \multicolumn{1}{c}{ LCAF origin } & LCAF drainage & \multicolumn{1}{c}{ Outcome } \\
\hline 1 & $22 / \mathrm{F}$ & Left septum & LV & Spontaneous healing at 6 mo \\
2 & $26 / \mathrm{M}$ & Left septum & LV & Persistence for 37 mo after \\
surgical intervention & No \\
& & & & Spontaneous healing at 6 mo \\
3 & $32 / \mathrm{F}$ & Left septum & LV & Spontaneous healing at 6 mo \\
5 & $42 / \mathrm{M}$ & Left septum & LV & Spontaneous healing at 6 mo \\
6 & $46 / \mathrm{M}$ & Left septum & LV & Spontaneous healing at 6 mo \\
7 & $54 / \mathrm{M}$ & Left septum & LV & Spontaneous healing at 1 mo \\
8 & $30 / \mathrm{F}$ & Left septum & LV & Spontaneous healing at 1 mo \\
9 & $31 / \mathrm{M}$ & Left septum, LV apex, & LV & No \\
& & lateral wall, AL PM & LV & Percutaneous closure
\end{tabular}

$L C A F$, Left coronary artery fistula; $L V$, left ventricular; $A L P M$, anterolateral papillary muscle. 


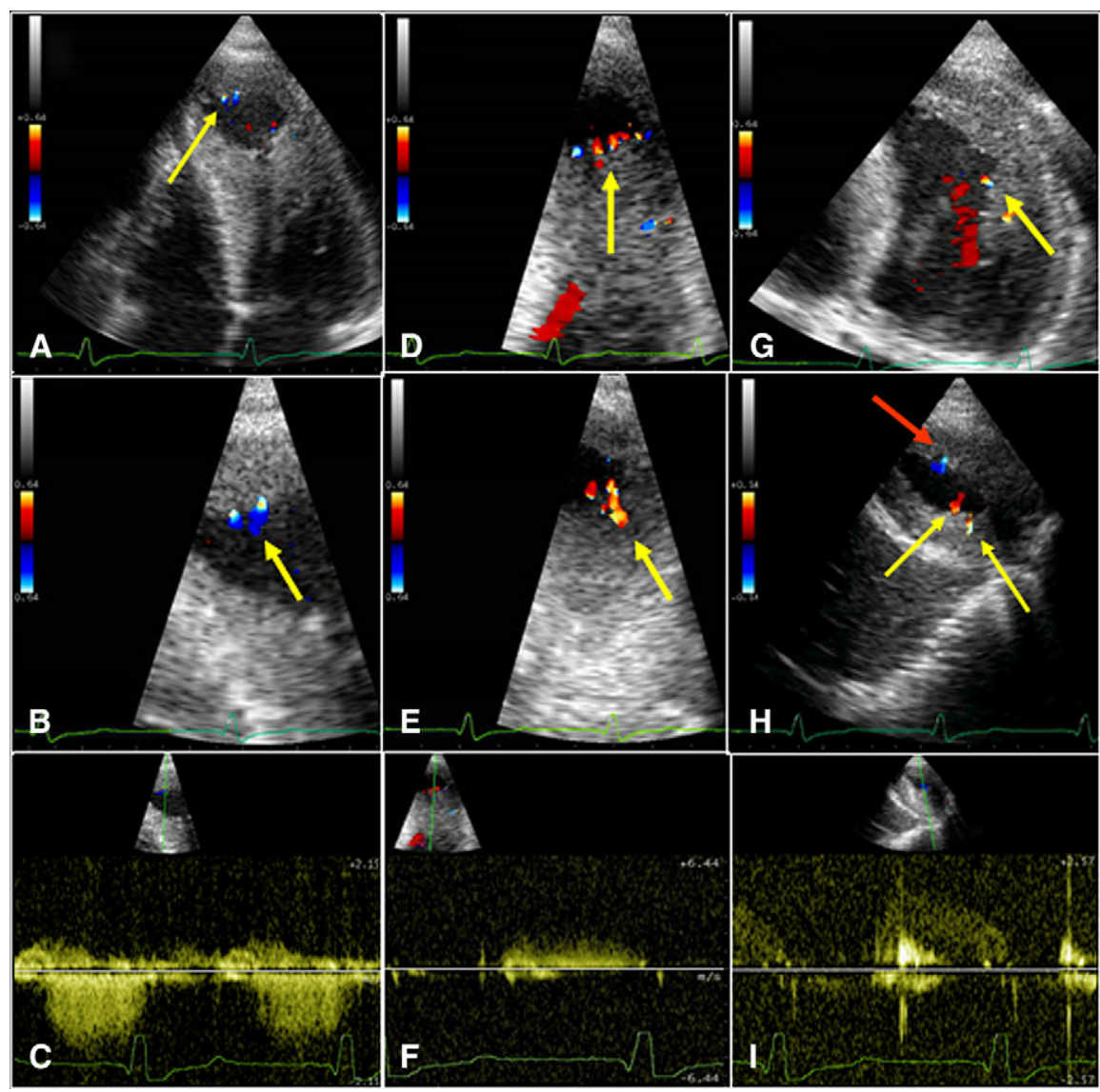

FIGURE 3. Multiple left coronary artery fistulas (LCAFs) in a 31-year old man with hypertrophic cardiomyopathy operated on from both the transaortic and apical approaches for severe midventricular obstruction. Multiple small LCAFs (arrows) draining in the left ventricular cavity were documented, originating from the apex (A-C), lateral wall (D-F, H, and I), and anterolateral papillary muscle (G). Continuous-wave Doppler ultrasound flow velocity recording showed maximal velocities ranging from 1.48 to $1.74 \mathrm{~m} / \mathrm{s}$, which are equivalent to a pressure decrease from 9 to $11 \mathrm{~mm} \mathrm{Hg}(\mathrm{C}, \mathrm{F}$, and I). Flow began at the end of isovolumic relaxation and lasted for the rest of diastole. All LCAFs spontaneously healed within 2 months from surgical intervention.

left side of the ventricular septum at the site of myectomy and draining into the LV outflow tract in 7 patients (Figure 1). The timing of LCAF flow was holodiastolic, beginning after the closure of the aortic valve leaflets, with an average early diastolic maximal velocity of $3.2 \mathrm{~m} / \mathrm{s}$, which is equivalent to an average pressure decay of $42 \mathrm{~mm} \mathrm{Hg}$. Only a 31-year-old man with massive LV hypertrophy and a severe midventricular obstruction (patient no. 8 in Table 1) operated on both from the transaortic and apical approaches showed multiple small LCAFs in the apex, septum, lateral wall, and anterolateral papillary muscle (Figure 3, arrows). In this patient LCAF flow started in middiastole, with maximal velocity ranging from 1.48 to $1.74 \mathrm{~cm} / \mathrm{s}$ (pressure decrease, 9 to $11 \mathrm{~mm} \mathrm{Hg}$ ).

A 72-year-old woman (patient no. 9) who had recurrence of obstruction and symptoms 2 years after percutaneous alcohol septal ablation was found postoperatively to have a wide LCAF entering the LV cavity from the anterior wall, generating a high-velocity holodiastolic flow directed toward the ventricular septum that was easily differentiated from a mild aortic regurgitation jet (Figure 4, $A-C$ ). Peak early diastolic flow velocity was higher than that of aortic regurgitation ( $4.33 \mathrm{vs} 3.18 \mathrm{~m} / \mathrm{s}$ ), and the derived pressure decay was $73 \mathrm{~mm} \mathrm{Hg}$ (Figure 4, $C$ and $D$ ).

\section{Follow-up}

At 6 months, LCAFs could still be detected in 2 patients but had spontaneously disappeared in the remaining 7 patients (Table 1). Of the 2 patients with persistent fistulas, the first (patient no. 2 in Table 1) was a young male patient with severe LV hypertrophy of the septum and marked intramural fibrosis that was documented as late gadolinium enhancement by means of cardiac magnetic resonance. LCAFs persisted at late follow-up (37 months) without any evident hemodynamic relevance or effect on clinical course. However, the second patient, the woman with the wide anterior wall LCAF (patient no. 9 in Table 1), had progressive dyspnea believed to be secondary to the hemodynamic 


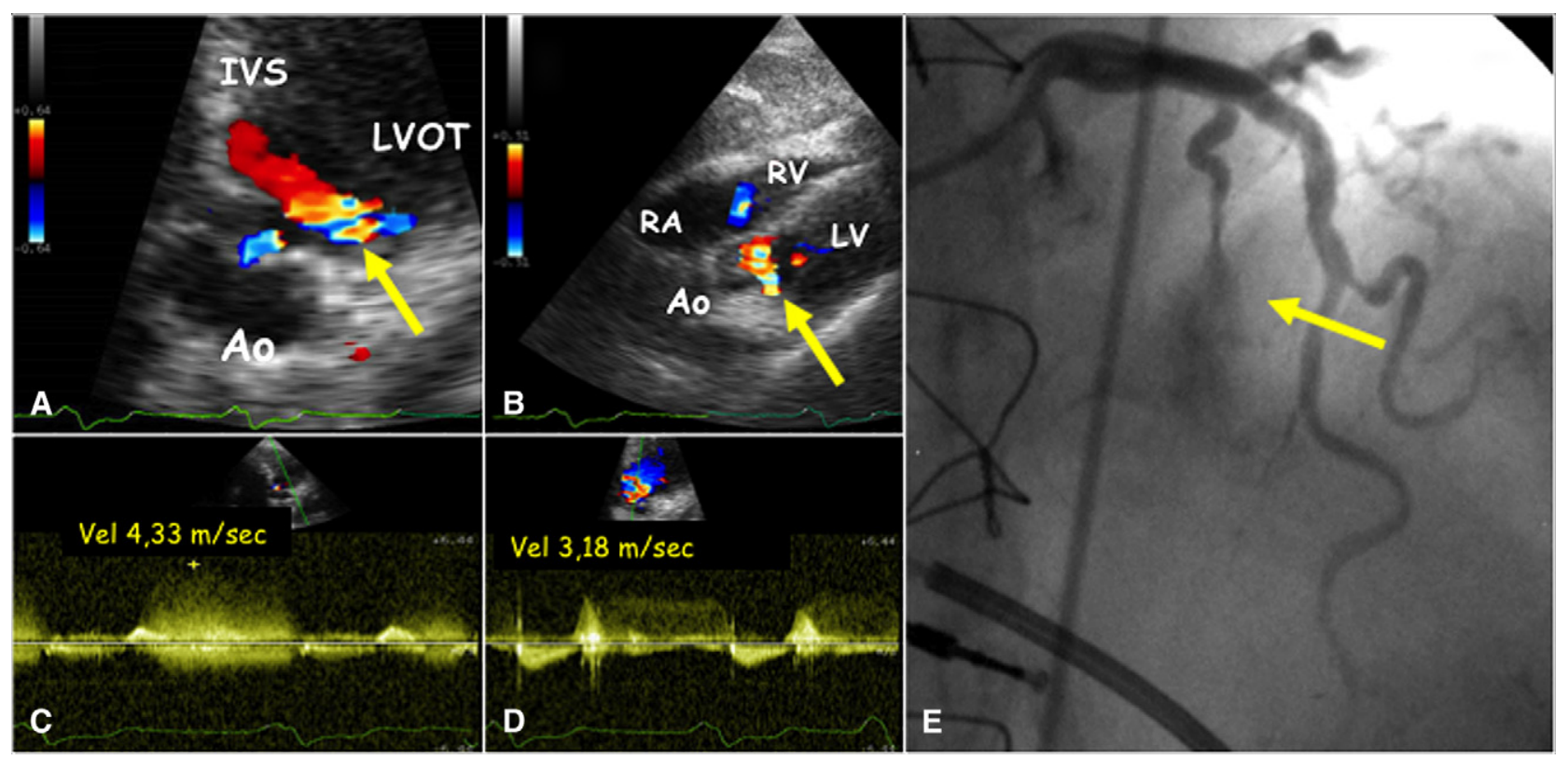

FIGURE 4. Large persistent left coronary artery fistulas (LCAFs) in a 72-year-old woman with hypertrophic cardiomyopathy with prior alcohol septal ablation. A magnified, apical 4-chamber off-axis view (A) and a subcostal, 4-chamber off-axis view (B) show wide, red-encoded flow entering the left ventricular cavity from the anterior wall (yellow arrows) caused by LCAFs that is easily differentiated from a mild aortic regurgitation jet simultaneously present in the left ventricular outflow tract (LVOT). The jet shows substantial variance, reflecting high-velocity flow. IVS, Interventricular septum; Ao, aorta; RA, right atrium; $R V$, right ventricle; $L V$, left ventricle. Continuous-wave Doppler recordings (C and $\mathrm{D})$ showed high maximal early diastolic velocity of $4.33 \mathrm{~m} / \mathrm{s}(\mathrm{a}$ derived pressure decay of $73 \mathrm{~mm} \mathrm{Hg}$ ) compared with $3.18 \mathrm{~m} / \mathrm{s}$ for the aortic regurgitation jet. A coronary angiogram confirmed the presence of a large first septal perforator branch fistula spraying in the left ventricular cavity (E, arrow).

overload after an initial improvement in symptoms. At 6 months, while in NYHA class II, she experienced hypokinesia of the LV apex and moderate functional mitral regurgitation. She required urgent hospital admission 17 months postoperatively because of severe progression of symptoms (to NYHA functional class III-IV). An angiographic study confirmed the presence of a large first septal branch fistula (Figure 4,E) and diminished distal flow in the left anterior descending coronary artery, suggesting a steal phenomenon or sclerosis from the alcohol injection. After percutaneous closure of the LCAF with a covered stent in the left anterior descending coronary artery, the fistula disappeared. Two months later, the patient had improved to NYHA class II, the LV regional wall motion abnormalities had resolved, and the residual degree of mitral regurgitation was mild.

\section{DISCUSSION}

\section{Diagnosis of Surgical LCAFs in Patients With HCM}

The present series is the first study of the prevalence of postoperative LCAFs in an HCM cohort undergoing septal myectomy. We found that LCAFs, as a result of surgical injury to the intramyocardial vessels, are commonly visualized at echocardiographic analysis in the early days or months after an extended surgical myectomy, with an overall prevalence of $23 \%$. Of note, a similar prevalence $(19 \%)$ was reported in a retrospective HCM series from Stanford University. ${ }^{19}$
The diagnosis of LCAFs by means of transthoracic echocardiographic analysis is relatively simple when performed by an experienced operator who is aware of their existence and typical diagnostic features. ${ }^{9,10,13-19}$ Unless specifically sought, however, LCAFs are easily missed. Moreover, their prevalence is largely determined by the time interval between surgical intervention and echocardiographic assessment because of the tendency of the fistulas to heal spontaneously in the first postoperative weeks.

\section{Clinical Relevance}

In our series most postoperative LCAFs were small and had no evident effect on clinical course. In 7 of the 9 patients with fistulas, these could no longer be visualized at 6 months, suggesting that spontaneous closure had occurred after a physiological healing process. Unlike congenital coronary fistulas draining in the right ventricle, which can lead to dilatation of the coronary arteries and congestive heart failure, ${ }^{5}$ LCAFs are usually associated with limited hemodynamic burden because of the high intracavitary LV pressures and small resulting pressure gradient between the vessel and cavity. ${ }^{5,6,14-19}$ These observations are consistent with the benign outcome of LCAFs in most of our patients, as well as with the limited existing literature..$^{9-19,23}$

An important exception to this principle, however, was observed in our series. One patient with a single, large 
anterior wall LCAF had severe symptom progression associated with regional systolic dysfunction and functional mitral regurgitation, likely because of a coronary steal phenomenon. ${ }^{2,5,14,16,24}$ Marked improvement after percutaneous closure of the LCAF provided evidence of its causal link with these functional abnormalities, pointing to the clinical relevance of the fistula. Therefore, although rarely severe, iatrogenic LCAFs are a complication of septal myectomy that might occasionally have a critical effect on outcome after surgical intervention. Of note, this patient had a prior history of percutaneous septal alcohol ablation. It is therefore tempting to speculate that by creating a large transmural scar within the septum, ${ }^{25}$ such a procedure might negatively affect the potential for spontaneous healing of LCAFs in the event of a subsequent surgical myectomy. Such a hypothesis deserves further investigation. Of note, surgical myectomy after alcohol ablation is known to be fraught with increased morbidity and mortality compared with the first-line surgical approach. ${ }^{26}$

\section{Implications for Management}

Based on the present observations, it is reasonable to propose that the presence of large LCAFs can be specifically sought by means of visual inspection in patients with HCM undergoing surgical myectomy, preferably with the aid of selective left coronary perfusion. Furthermore, in patients with cardiac symptoms postoperatively, it is important to rule out LCAFs as a potential cause.

Postoperatively, LCAFs are frequently found during routine echocardiographic evaluation. In the absence of symptoms or evidence of hemodynamic overload, however, a conservative approach can be safely recommended based on the high rate of spontaneous closures observed in the present study. In our series the prevalence of LCAFs decreased from $23 \%$ at 1 month to $5 \%$ at 6 months after surgical intervention. Accordingly, Choi and associates ${ }^{18}$ documented the spontaneous closure of LCAFs 10 days after myectomy, whereas in the study of Jebara and coworkers, ${ }^{8} 2$ of 3 postoperative fistulas closed spontaneously after 7 and 18 months, respectively. In those patients with persistent or worsening symptoms despite successful surgical myectomy and relief of dynamic outflow tract obstruction, ${ }^{22}$ however, further evaluation, including invasive procedures, is mandatory to further elucidate the hemodynamic burden of persisting LCAFs, their effect on coronary flow, and the potential for specific treatment.

\section{CONCLUSIONS}

In patients with HCM, LCAFs are common in the early period after surgical myectomy, although their echocardiographic prevalence is largely determined by timing of postoperative assessment and operator awareness. Most LCAFs have no clinical relevance, and their fate is spontaneous healing. Occasionally, however, fistulas can persist and result in symptoms requiring therapeutic intervention. The role of prior alcohol septal ablation in determining LCAF persistence requires further investigation.

\section{References}

1. Yamanaka O, Hobbs RE. Coronary artery anomalies in 126,595 patients undergoing coronary arteriography. Catheter Cardiovasc Diagn. 1990;21:28-40.

2. Lisanti P, Serino W, Petrone M. Multiple coronary artery-left ventricle fistulas in a patient with apical hypertrophic cardiomyopathy: an unusual cause of angina pectoris. G Ital Cardiol. 1988;18:858-61.

3. Alyan O, Ozeke O, Golbasi Z. Coronary artery-left ventricular fistulae associated with apical hypertrophic cardiomyopathy. Eur J Echocardiogr. 2006;7:326-9.

4. Elliott PM, Brecker SJ, McKenna WJ. Left ventricular opacification during selective intracoronary injection of echocardiographic contrast in patients with hypertrophic cardiomyopathy. Heart. 2000;83:7-10.

5. Lowe JE, Adams DH, Cummings RG, Wesly RLR, Philips HR. The natura history and recommended management of patients with traumatic coronary artery fistulas. Ann Thorac Surg. 1983;36:295-305.

6. Lee $\mathrm{KMH}$, Pichard AD, Lindsay J. Acquired coronary artery-left ventricular pseudoaneurysm fistula after myocardial infarction. Am J Cardiol. 1989;64 824-5.

7. Iannone LA, Iannone DP. Iatrogenic left coronary artery fistula to left ventricle following PTCA: a previously unreported complication with non-surgical management. Am Heart J. 1990;120:1215-7.

8. Jebara VA, Corbi P, Dreyfus G, Acar C, Chachques JC, Rovani X, et al. Postoperative iatrogenic coronaro-ventricular fistula. Ann Chir. 1989;43:643-5.

9. Marek A, Rey JL, Tribouilloy C, Jarry G, Avinee P, Lesbre JP, et al. Fistule coronaroventriculaire gauche iatrogène postopératoire mise en evidence par le Doppler à codage couleur. Arch Mal Coeur. 1991;84:419-23.

10. Unger Ph, Moreels M, Stoupel E, de Cannière D. Acquired coronary fistula after left ventricular de-airing by apical needle aspiration. Eur J Echocardiogr. 2008;9 410-1.

11. Buchwald A, Wiegand V, Kreuzer H. Koronarfistel zum rechtsventriculären Ausflusstrakt als Komplikation einer kombiniert transaortalen-transrechtsventricularen Myektomie bei hypertropher obstrucktive Kardiomyopathie. Z Kardiol. 1988;77: 61-3.

12. Gildein HP, Kleinert S, Layangool T, Wilkinson JL. Acquired coronary artery fistula in children after ventricular septal myectomy of the right or left ventricular outflow tract. Am Heart J. 1995;130:1124-6.

13. Voet J, De Sutter J, De Pauw M. Diagnosis of a coronary artery fistula thirty years after myectomy for septal hypertrophy. Acta Cardiol. 2000;55:197-8.

14. Bax JJ, Raphael D, Bernard X, Vanoverschelde JL. Echocardiographic detection and long-term outcome of coronary artery-left ventricle fistula after septal myectomy in hypertrophic obstructive cardiomyopathy. J Am Soc Echocardiogr. 2001 14:308-10.

15. Andreen KM, Klarich KW, Gilman G, Miller FA Jr, Reeder GS. Septal perforator to left ventricular outflow tract fistula. J Am Soc Echocardiogr. 2001;14:840-1.

16. Awasthi A, Wormer D, Heggunje PS, Obeid A. Long-term follow-up of acquired coronary artery fistula after septal myectomy for hypertrophic cardiomyopathy. J Am Soc Echocardiogr. 2002;15:1104-7.

17. Sooudi SK, Ahmed S, Nekkanti R, Nanda NC. Transthoracic echocardiographic demonstration of septal perforator coronary arteries-left ventricle fistula. Echocardiography. 2003;20:197-8.

18. Choi YJ, You CW, Park MK, Park JI, Kwon SU, Lee S-C, et al. Spontaneous closure of iatrogenic coronary artery fistula to left ventricle after septal myectomy for hypertrophic obstructive cardiomyopathy. J Korean Med Sci. 2006;21:1111-4.

19. Chenzbraun A, Pinto FJ, Meyer B, Stinson EB, Popp RL. Frequency of acquired coronary-cameral fistula after ventricular septal myectomy in hypertrophic cardiomyopathy. Am J Cardiol. 1993;71:1244-6.

20. Yacoub M, Onuzo O, Riedel B, Radley-Smith R. Mobilization of the left and right fibrous trigones for relief of severe left ventricular outflow obstruction. J Thorac Cardiovasc Surg. 1999;117:126-33.

21. Minakata K, Dearani JA, Nishimura RA, Maron BJ, Danielson GK. Extended septal myectomy for hypertrophic obstructive cardiomyopathy with anomalous mitral papillary muscles or chordae. J Thorac Cardiovasc Surg. 2004;127: 481-9.

22. Maron BJ, McKenna WJ, Danielson GK, Kappenberger LJ, Kuhn HJ Seidman CE, et al. American College of Cardiology/European Society of Cardiology clinical expert consensus document on hypertrophic cardiomyopathy. A report of the American College of Cardiology Foundation Task Force on Clinical 
Expert Consensus Documents and the European Society of Cardiology Committee for Practice Guidelines. J Am Coll Cardiol. 2003;42:1687-713.

23. Sarkis A, Lehnert F, Diebold B, Monin JL, Cosma C, Castaldo F, et al. Left coronaro-ventricular fistula after septal myectomy. Arch Mal Coeur Vaiss. 1992;85:457-60.

24. Strange JW, Bucciarelli-Ducci C, Mathur A, Pennell DJ. Multiple coronary fistulae: a cause of subendocardial ischemia. Circulation. 2008;117:853-6.
25. Valeti US, Nishimura RA, Holmes DR, Araoz PA, Glockner JF, Breen JF, et al. Comparison of surgical septal myectomy and alcohol septal ablation with cardiac magnetic resonance imaging in patients with hypertrophic obstructive cardiomyopathy. J Am Coll Cardiol. 2007;49:350-7.

26. ElBardissi AW, Dearani JA, Nishimura RA, Ommen SR, Stulak JM, Schaff HV. Septal myectomy after previous septal artery ablation in hypertrophic cardiomyopathy. Mayo Clin Proc. 2007;82:1516-22. 